\title{
VISUAALISTEN HAHMOTUSTOIMINTOJEN RYHMÄINTERVENTIO KOULUSSA
}

\section{Johdanto}

Visuaaliset hahmotustoiminnot eli se, miten saamme havainnoimalla tietoa ympäröivästä maailmasta, ovat olennaisia jokapäiväisessä arjessamme. Neuropsykologisesta kirjallisuudesta visuaalisille hahmotustoiminnoille on löydettävissä monia käytössä olevia käsitteitä ja luokitteluita (mm. Allen 2003, Kaufman 2007, Hegarty \& Waller 2004, Willcutt ym. 2005). Perinteisesti hahmottamisella tarkoitetaan nähdyn ymmärtämistä, kun taas havaitsemisella tarkoitetaan aistimuksen siirtymistä aivokuorelle ja sen ominaisuuksien käsittelyä (Isomäki 2015). Kun havaintoon liitetään tulkintoja ja se yhdistyy aikaisempiin tietovarastoihin, havaitseminen muuttuu hahmottamiseksi (Isomäki 2015). Nykyajan lapset ja nuoret kasvavat ympäristössä, jossa hahmottamiseen liittyvät toiminnot ovat tärkeitä esimerkiksi arjen teknologian käytössä. Voidaan olettaa, että koulussa ja tulevaisuuden työpaikoissa hyvän visuaalisen hahmotuskyvyn vaatimus tulee korostumaan.

Arjessa selviytyäksemme tarkan havaintotiedon saaminen edellyttää aistien normaalia ja häiriötöntä toimintaa sekä useiden aivoalueiden monimutkaista, yhtäaikaista ja virheetöntä yhteistyötä. Havaintotoiminnot jaetaan usein karkeasti kahteen eri järjestelmään: perifeeriseen näköjärjestelmään ja aivokuoren visuaaliseen järjestelmään (Ahonniska \&t Aro 2001). Perifeerinen näköjärjestelmä kattaa silmän ja näköhermon toiminnan (Vanni 2006), kun taas aivokuoren visuaaliseen näköjärjes- telmään kuuluu useita eri alueita. Aivokuoren visuaaliseen näköjärjestelmään kuuluu takaraivolohkojen, alemman ohimolohkon sekä päälakilohkon alueita, joissa aivoihin tullutta tietoa käsitellään kahdessa suhteellisen erillisessä prosessointisysteemissä: ventraalisessa ja dorsaalisessa radassa (Ungerleider \&t Mishkin 1982, Courtney \& Ungerleider 1997). Visuaalisen tiedon prosessointi on suurelta osin simultaaniprosessointia eli tiettyä havaintoa tulkitaan samanaikaisesti eri puolilla aivoja.

Lasten visuaaliset hahmotusvaikeudet voivat näyttäytyä arjessa eri tavoin yksilöllisesti vaihdellen. Tämä tarkoittaa sitä, että eri aivoalueiden kehityksen ja toiminnan ongelmat voivat luoda tiedonkäsittelyn pulmia, jotka arjessa todetaan hahmottamisen häiriöinä (Isomäki 2015). Lasten hahmottamisen vaikeudet voivat esiintyä laaja-alaisina, hahmottamisen useiden eri osa-alueiden heikkoutena tai huomattavasti tarkkarajaisempina vaikeuksina (Ahonniska \&t Aro 2001). Yleisesti hahmotushäiriöstä voidaan puhua silloin, kun häiriö ilmenee käyttäytymisen tasolla jonkin iänmukaisen prosessoinnin oppimisen hitautena tai vaikeutena ja visuaalisen prosessoinnin taidot ovat psykologisissa tutkimuksissa mitattuina ikäryhmän normaalivaihtelua vähintään yhden keskihajonnan heikompia (Isomäki 2015). Tyypillisimmät kehitykselliset hahmottamisen häiriötyypit ovat visuaalisen tarkkaavuuden ja avaruudellisen hahmottamisen vaikeudet. Visuaalisen tarkkaavuuden vaikeus näkyy tilanteissa, joissa vaaditaan tarkkaa paikallaan 
olevien tai liikkuvien visuaalisten ärsykkeiden havaitsemista. (Isomäki 2015.) Avaruudellisen hahmottamisen vaikeudella tarkoitetaan haasteita, jotka tulevat esiin lapsen kyvyssä hahmottaa visuaalista informaatiota kaksitai kolmiulotteisessa ympäristössä (Korkman ym. 2008). Hahmotushäiriöt voivat esiintyä myös erilaisten oppimisvaikeuksien taustalla esimerkiksi ei-kielellisenä oppimisvaikeutena (Rourke 1995).

Visuaaliset hahmotushäiriöt voivat tuottaa monenlaisia haasteita arjen toimintoihin kuten leikkiin, vapaa-ajan viettoon, itsestä huolehtimiseen ja sosiaaliseen kanssakäymiseen (Schneck 2010). Päivittäisten toimintojen lisäksi vaikeudet voivat tulla esiin toiminnoissa, joissa käytetään erilaisia välineitä, kuten askartelussa ja ruuanlaitossa. Visuaaliset hahmotushäiriöt saattavat tulla esiin myös oppimisvaikeuksina ja tuottaa vaikeuksia esimerkiksi lukemisessa, tavuttamisessa, kirjoittamisessa sekä matematiikassa (mm. Assel ym. 2003, Cheng \& Mix 2012, Holmes ym. 2008, Schneck 2010).

Lasten hahmotushäiriöiden kuntoutusta sekä interventioita on tutkittu huomattavasti vähemmän kuin kieleen ja lukemiseen liittyvien vaikeuksien kuntoutusta. Yleisessä diagnoosiluokituksessa, kuten The Diagnostic and Statistical Manual of Mental Disorders 5:ssä (American Psychiatric Association 2015), ei tunneta hahmotusvaikeuksia. Kuitenkin viime vuosina Suomessa on alettu tutkia hahmotusvaikeuksia ja niiden kuntoutusta. Suomessa alkanut hahmotusvaikeuksien kuntoutukseen tähtäävä nelivuotinen hanke (2014-2017) on toteutettu useamman toimijan yhteistyönä (hahku.fi). Tällä hetkellä hahmotusvaikeuksia kuntoutetaan Suomessa neuropsykologisin keinoin. Mikäli lasten hahmotusvaikeudet ovat lieviä tai niitä ei ole tarkemmin tutkittu psykologin tutkimuksessa, usein ainoaksi avuksi jäävät koulun ja erityisopetuksen tarjoamat tukitoimet. Visuaalisen hahmottamisen vaikeudet eivät aina ilmene laaja-alaisina mutta voivat silti haitata arkea ja oppimista. Lieviä haasteita omaavien sekä neuropsykologisen kuntoutuksen ulkopuolelle jäävien lasten kannalta olisi tärkeää luoda koulun sisäl- le interventiomalleja hyödyntäen kouluissa jo olevia asiantuntijapalveluita, kuten psykologipalveluita, jotka oppilas- ja opiskeluhuoltolaki edellyttää kaikkiin peruskouluihin.

\section{Interventiomalli}

Tässä katsauksessa esittelyn kohteena on malli, jossa lievien hahmotusvaikeuksien interventio on integroitu koulun arkeen hyödyntäen koulussa jo olevia asiantuntijapalveluita. Interventiomallin avulla pyritään vahvistamaan hahmotustoimintoja mahdollisimman varhaisessa vaiheessa ennen kuin ne mahdollisesti vaikeutuvat ja alkavat näkyä laajemmin arjen toimintakyvyssä. Aihe on tärkeä ja ajankohtainen, sillä visuaalisten hahmotustoimintojen interventioita on tutkittu vielä varsin niukasti ja tutkimusta erilaisista visuaalisten hahmotustoimintojen interventioista kaivataan lisää (Chabani \&t Hommel 2014, Uttal ym. 2012). Suomessa on tehty kokeiluja, joissa kuntoutus ja tietyn taidon harjoittelun tukeminen on integroitu päiväkodin ja koulun päivänohjelmaan (von Wendt 2003). Kyseiset toimintamallit ovat taloudellisesti edullisia, sillä lasten on mahdollista saada enemmän tukea taitojen vahvistamiseen pienemmillä kustannuksilla kuin turvautumalla puhtaasti ostopalveluna hankittuun kuntoutukseen.

Katsauksen kohteena olevan interventiomallin tavoitteena oli antaa tukea lasten arkiympäristössä lapsille, joilla havaittiin lieviä visuaalisten hahmotustoimintojen haasteita. Osalla lapsista lievät haasteet saattavat olla itsestään korjautuvia kypsymisen myötä ja toisilla lievien haasteiden ilmaantuminen voi ennakoida syveneviä vaikutuksia. Lievienkin haasteiden tukeminen on merkityksellistä, sillä pahimmillaan visuaalisten hahmotustoimintojen vaikeuksilla on taipumus laajentua ja syventyä, mikä saattaa näkyä joidenkin lasten kohdalla myöhemmin laajoina arjen toimintarajoitteina (mm. Assel ym. 2003, Cheng Et Mix 2012, Holmes ym. 2008, Schneck 2010).

Visuaalisten hahmotusvaikeuksien intervention järjestäminen mahdollistui osana Helsingin kaupungin Koulutuksellista Tasaarvo -hanketta. Mallissa intervention kohtee- 
na olivat ensimmäisen luokan oppilaat, joilla havaittiin laaja-alaisen erityisopettajan teettämässä VENNY 1 -kartoituksessa (Koivula 2012) visuaaliseen hahmottamiseen mahdollisesti liittyviä vaikeuksia ja jotka saivat kartoituksesta korkeintaan neljä pistettä. VENNY 1 -kartoitusosio koostuu kolmesta osasta: pisteikkö-, sarjoitus- ja palikkarakennelmatehtävästä. Kartoituksen maksimipistemäärä on seitsemän pistettä. Kartoituksen kaksi ensimmäistä osaa, pisteikkö- ja sarjoitustehtävä, toteutettiin luokassa tehtävänä ryhmätestauksena (kesto $45 \mathrm{~min}$ ), ja palikkarakennelmatehtävän oppilas suoritti yksin (kesto noin 5 - 10 min/oppilas). VENNY 1 -kartoitusosio mittaa suhteellisen kapea-alaisesti visuaalisia hahmotustoimintoja, mutta menetelmä valittiin käyttöön, koska markkinoilta ei löytynyt vielä vastaavaa tutkittua ja normitettua ryhmäseulontaan soveltuvaa menetelmää. Kuitenkin laadullisesti tarkasteltuna kartoitusosiossa suoriutumisessa vaaditaan visuaalista havaitsemista, spatiaalista prosessointia, visuokonstruktiivisia taitoja, kokonaisuuksien ja yksityiskohtien hahmottamista sekä visuaalista tarkkaavaisuutta, mutta heikkoon tulokseen saattavat vaikuttaa myös muut tekijät, esimerkiksi toiminnanohjauksen haasteet, tarkkaavuuden pulmat tai motivaation puute.

Visuaalisten hahmotustoimintojen kartoitukset tehtiin alkusyksystä 2013 ja 2014 20:ssä yleisopetuksen luokassa. Kartoitukseen osallistuneista oppilaista löytyi 55 kriteerit täyttänyttä oppilasta, joista 32 oppilasta osallistui visuaalisten hahmotustoimintojen interventioon. Loput 23 kriteerit täyttävää oppilasta jätettiin intervention ulkopuolelle, jotta tulevaisuudessa on mahdollista tutkia intervention vaikuttavuutta. Kaikille kriteerit täyttäville oppilaille tehtiin alkukartoituksessa käytetty kartoitus uudelleen ensimmäisen luokan lopussa. Interventioon osallistuneet oppilaat valikoituivat niistä kouluista, joiden arjessa oli mahdollista toteuttaa tässä katsauksessa esiteltävä interventiomalli.

Interventiomallin kulmakivenä oli lapsen aktiivinen ja systemaattinen harjoittelu sekä visuaalisten hahmotustoimintojen tukeminen lapsen omassa arkiympäristössä. In- terventiomallissa hyödynnettiin monia neuropsykologisessa kuntoutuksessa käytettäviä rinnakkaisia lähestymistapoja, kuten suoraa kognitiivista harjoittelua, strategiaharjoittelua, toiminnasta annettavaa palautetta, apuvälineiden käytön ohjaamista ja metakognitiivisten taitojen, kuten ongelmanratkaisutaitojen, tavoitteellisemman toiminnan säätelyn, oman toiminnan ohjaamisen ja monitoroinnin sekä emotionaalisen itsesäätelyn vahvistamista (Nukari ym. 2012), mutta interventiota ei voida kuitenkaan verrata neuropsykologiseen kuntoutukseen. Toisena interventiomallin keskeisenä ajatuksena oli dynaamisen arvioinnin viitekehys, joka perustuu Vygotskyn (1978) sosiokulttuuriseen teoriaan, erityisesti käsitykseen lähikehityksen vyöhykkeestä, sekä Feuersteinin teoriaan ohjaavasta opetuksesta (Feuerstein ym. 1979). Termi dynaaminen arviointi viittaa "sellaiseen lapsen näkökulman, oppimisen, ajattelun ja ongelmanratkaisun arviointiin, jossa lasta ohjataan aktiivisesti. Ohjauksen tavoitteena on muokata yksilön kognitiivisia toimintoja ja tarkkailla muutoksia oppimisen menetelmissä sekä ongelmanratkaisun tavoissa" (Tzuriel 2002).

Intervention toteutuksesta vastasivat koulupsykologi ja laaja-alainen erityisopettaja. Kuhunkin interventioryhmään osallistui 7-9 oppilasta. Interventio oli integroitu oppilaiden koulupäiviin ja koulun puolelta resursoitu erityisopetuksesta. Yksi interventiokerta kesti yhden oppitunnin ajan eli 45 minuuttia ja se toteutettiin suunnilleen viikoittain oppilaiden ensimmäisenä lukuvuotena. Kokonaisuudessaan interventio kesti keskimäärin 24 viikkoa. Jokainen yksittäinen interventiokerta sisälsi monipuolisesti visuaalisten hahmotustaitojen harjoittelua, kuten lajittelua, yksityiskohtien erottamista, sarjoittamista, mallista kopioimista sekä rakentelua.

Harjoittelu ja käytetyt materiaalit valittiin kunkin interventioryhmän tarpeiden ja etenemisen mukaan. Intervention aikana lapsia ohjattiin suoran harjoittelun lisäksi käyttämään strategioita, kuten visuaalisen tarkkaavaisuuden suuntaamista, oman toiminnan suunnittelua, tarkistamista, nimeämistä ja kokonaisuuksien pilkkomista pienempiin osiin. Lisäksi 
lasten tarkoituksenmukaista toimintaa pyrittiin vahvistamaan kannustavan henkilökohtaisen palautteen sekä myönteisen ryhmähengen luomisen avulla. Lasten metakognitiivisia taitoja vahvistettiin muun muassa ohjaamalla lapsia havainnoimaan ja reflektoimaan omaa toimintaansa, käyttämään erilaisia ongelmanratkaisutaitoja sekä säätelemään omaa toimintaansa ja käyttäytymistään. Interventiossa edettiin hiljalleen vaikeampiin tehtäviin sitten, kun vaatimustasoltaan helpommat tehtävät olivat lapsella hallussa. Interventiossa hyödynnettiin konkreettisena materiaalina erilaisia visuaalisia hahmotustoimintoja vaativia tehtäviä ja pelejä, kuten visuomotorisia taputusleikkejä, sekä Early Learningin (www. earlylearning.fi/product_catalog.php/hahmotus-ja-tarkkuuspelit) ja Tevella Oy:n (www. tevella.fi) visuaalisen hahmottamisen materiaalia sekä VENNY 2 -kuntoutusmateriaalia (Koivula 2012).

\section{Kuvaus interventiokerrasta}

1. Peilileikki: leikin tavoitteena on jäljitellä toisen henkilön kehon asentoa mahdollisimman tarkasti yksityiskohdat huomioiden.

2. Tehtävätyöskentely: tehtävä, jossa tulee löytää mallin kanssa täysin samanlaiset kuvat ärsykekuvioiden joukosta.

3. Konkreettinen työskentely: eriväristen ja eri lajia edustavien kumieläinten lajittelu tietyn ominaisuuden mukaan.

\section{Lopuksi}

Katsauksen tarkoituksena oli esitellä malli, jossa interventio on integroitu osaksi koulun arkea jo siellä olevien asiantuntijapalveluiden turvin. Koulu on lasten luonnollinen, lähes päivittäinen toimintaympäristö, jossa on paljon osaamista ja asiantuntemusta lapsista ja heidän arjen toimintarajoitteistaan. Mallissa toteutettu visuaalisten hahmotustoimintojen interventio hyödyntää koulussa jo olevia re- sursseja systemaattisemmin ja tehokkaammin vastaamaan lasten tarpeita. Interventiomalli toteutettiin ryhmämuotoisesti, koska ryhmässä toimiminen on kouluikäisen lapsen ja nuoren luonnollinen toimintaympäristö. Ryhmässä lasten toiminta on usein spontaanimpaa ja vastaa paremmin lasten todellista toimintaa (Nieminen 1999). Ryhmässä pääsevät myös esiin lasten mahdolliset muut haasteet, kuten tarkkaavaisuuden, toiminnanohjauksen tai sosiaalisten taitojen haasteet, joihin ryhmä tarjoaa oman tukensa. Lisäksi ryhmän tarjoamien vertailukohtien kautta ryhmän jäsenet voivat suhteuttaa omia vaikeuksiaan muiden toimintaan ja huomata, etteivät ole vaikeuksineen yksin (Nieminen 1999). Ryhmässä lapset voivat myös oppia muilta jäseniltä uusia ratkaisu- ja toimintamalleja. Lisäksi ryhmäinterventio mahdollistaa yhdessä toimimisen ja työskentelyn erilaisten pari- ja ryhmätehtävien, pelien ja leikkien myötä.

Koulu ympäristönä tarjoaa luonnollisen yhteydenpitomahdollisuuden lasten huoltajiin. Interventioon osallistuneiden lasten huoltajiin oltiin pääasiassa yhteydessä ennen intervention alkua sekä sen päättymisvaiheessa. Huoltajille annettiin lisäksi tarpeen mukaan tietoa oman lapsen etenemisestä sekä kotiin mahdollisesti käyttöönotettavista tukitoimista. Lisäksi osalle lapsista, joiden tuen tarve ei intervention jälkeen vähentynyt, saatettiin suositella tarkempaa psykologin tutkimusta. Tulevaisuudessa vastaavia interventiomalleja suunniteltaessa interventioon osallistuneiden lasten perhe ja muu arkiympäristö tulisi ottaa vielä selkeämmin ja järjestelmällisemmin mukaan prosessiin. Tämä mahdollistaisi intervention aikana esiin tulleen tiedon ja lasta hyödyntävien tukitoimien jakamisen tehokkaammin lapsen päivittäiseen arkeen.

Jotta interventiot saadaan koulussa kohdennettua niitä tarvitseville lapsille, tarvitaan parempia ja tutkittuja kartoitusmenetelmiä lievien haasteiden havaitsemiseen. Mallissa hyödynnettiin alku- ja loppukartoituksessa VENNY 1 -kartoitusosioita (Koivula 2012). VENNY 1 -kartoitusosiota ei ole tutkittu tieteellisesti, eikä mittarilla ole normiaineistoa. VENNY 1- kartoitusosio mittaa suhteellisen 
kapea-alaisesti visuaalisia hahmotustoimintoja, eikä sen perusteella pystytä tutkitusti ottamaan laaja-alaisesti kantaa hahmotustoimintojen haasteisiin tai visuaalisiin päättelytaitoihin. Laadullisesti tarkasteltuna voidaan olettaa, että kartoitusosiossa suoriutumisessa vaaditaan erilaisia visuaalisten hahmotustoimintojen osa-alueita, mutta mittari on mahdollisesti herkkä myös muille väliin tuleville tekijöille. Jatkossa on tärkeää kehittää visuaalisten hahmotustoimintojen ryhmäseulontaan käytettäviksi soveltuvia mittareita.

Kuntouttavien interventioiden kannalta on olennaista pyrkiä saamaan tietoa, miten annetulla interventiolla tai kuntoutuksella voidaan vaikuttaa lapsen arjessa esiin tulleisiin haasteisiin (Van Der Heyden ym. 2007). Interventio itsessään antaa paljon tietoa lapsen toiminnasta, mutta usein on myös perusteltua tehdä tarkempi psykologin tutkimus. Psykologin tutkimuksesta esiin tulleen tiedon perusteella voidaan ensisijaisesti suunnitella systemaattisempia ja kohdennettuja tukimuotoja lapsen ympäristöön lapsen vahvuudet ja haasteet huomioiden. Joskus hahmotusvaikeudet voivat osoittautua niin laaja-alaisiksi ja syviksi, ettei niiden vahvistaminen tuo merkittävää muutosta toimintakykyyn (Isomäki 2015). Tällöin lapsen arkiympäristöön tuotu tuki nousee tärkeäksi keinoksi.

Tulevaisuudessa koulujen sisällä tarvittavien interventioiden tarve tulee kasvamaan, mikäli tukea tarvitsevat lapset integroituvat nykyistä enemmän lähikouluihin. Kouluissa jo olevat asiantuntijapalvelut tulee rakentaa vastaamaan lasten haasteita. Uutta tutkimustietoa erilaisista kouluihin integroiduista interventioista tarvitaan lisää. Tulevaisuudessa olennaista olisi saada lisätietoa, miten visuaalisissa hahmotustoiminnoissa mahdollisesti havaitut myönteiset muutokset siirtyvät käytännön toimintaan vaikuttavalla ja merkityksellisellä tavalla. Interventioiden siirtovaikutuksia olisi jatkossa syytä arvioida laajemmin käytännön elämän ongelmien, sosiaalisen osallistumisen, elämänlaadun, emotionaalisen tasapainoisuuden ja oppiaineiden kannalta (Nukari ym. 2012). Siirtovaikutusten lisäksi tarvitaan tutkimustietoa siitä, kuinka pitkäkestoisia vaikutuksia interventioilla on mahdollista saavuttaa.

Tulosten merkitys: Interventiomalli havainnollistaa ja tuo tietoa siitä, miten kouluissa jo olevia asiantuntijapalveluita voidaan jatkossa kohdentaa systemaattisemmin tukemaan lasten haasteita. Mallin avulla koulujen palveluiden kohdistamista voidaan tehostaa ja suunnitella uudella tavalla.

Avainsanat: visuaalinen hahmottaminen, interventio, kouluinterventio

Juulia Lahdensuo, PsM, Helsingin kaupunki, opetusvirasto/perusopetuslinja

Maarit Virta, PsT, psykologian ja logopedian laitos, lääketieteellinen tiedekunta, Helsingin yliopisto

\section{Lähteet}

Ahonniska J, Aro T (2001) Hahmotusvaikeuksien kuntoutus. Teoksessa T Ahonen, T Aro (toim.) Oppimisvaikeudet: Kuntoutus ja opetus yksilöllisen kehityksen tukena. Atena, Jyväskylä.

Allen GL (2003) Functional families of spatial abilities: Poor relations and rich prospects. International Journal of Testing 3, 251-262.

American Psychiatric Association (2013) Diagnostic and statistical manual of mental disorders. American Psychiatric Association, Washington, DC.

Assel MA, Landry SH, Swank P, Smith KE, Steelman LM (2003) Precursors to mathematical skills: Examining the roles of visual-spatial skills, executive processes, and parenting factors. Applied Developmental Science 7, 27-38.

Chabani E, Hommel B (2014) Effectiveness of visual and verbal prompts in training visuospatial processing skills in school age children. Instructional Science 4, 5-15.

Cheng YL, Mix KS (2012) Spatial training improves children's mathematics ability. Journal of Cognition and Development 1, 2-11.

Courtney SM, Ungerleider LG (1997) What fMRI has taught us about human vision. Current Opinion in Neurobiology 7, 554-561.

Feuerstein R, Rand Y, Hoffman MB (1979) The dynamic assessment of retarded performers: The learning 
potential assessment device: Theory, instruments, and techniques. University Park Press, Baltimore.

Hahku - hahmottamisen kuntoutus [viitattu 13.01.2017]. Saatavissa: http://www.hahku.fi.

Hegarty M, Waller D (2004) A dissociation between mental rotation and perspective-taking spatial abilities. Intelligence 32, 175-191.

Holmes J, Adams JW, Hamilton C (2008) The relationship between visuo-spatial sketchpad capacity and children's mathematical skills. European Journal of Cognitive Psychology 20, 272-289.

Isomäki H (2015) Kummi 12: Ymmärrämmekö näkemäämme - visuaalisen hahmottamisen häiriöt. Jyväskylä: Niilo Mäki Instituutti.

Kaufman SB (2007) Sex differences in mental rotation and spatial visualization ability: Can they be accounted for by differences in working memory capacity? Intelligence 35, 211-223.

Koivula M (2012) VENNY 2 - Visuaalisten hahmotusvaikeuksien kuntoutus. Kariston Kirjapaino Oy, Hämeenlinna.

Korkman M, Kirk U, Kemp SL (2008) NEPSY-II - Lasten neuropsykologinen tutkimus, Käsikirja II. Bookwell 0y, Vaajakoski.

Nieminen P (1999) Lasten ryhmäkuntoutus. Teoksessa T Ahonen, T Aro (toim.) Oppimisvaikeudet. Kuntoutus ja opetus yksilöllisen kehityksen tukena. Juva, Atena, 47-59.

Nukari J, Poutiainen E, Nybo T, Hämäläinen P, Kalska H (2012) Neuropsykologisen kuntoutuksen vaikuttavuus. Psykologia 47, 1-21.

Rourke BP (1995) Introduction: The NLD syndrome and the white matter model. Teoksessa BP Rourke (toim.) Syndrome of nonverbal learning disabilities: Neurodevelopmental manifestations. Guilford, New York, NY.

Schneck CM (2010) Visual perception. Teoksessa J Case-Smith (toim.) Occupational Therapy for Children. Mosby, St. Louis, Missouri, 382-411.
Tzuriel D (2002) Cognitive education: The menace and hope. Teoksessa W Resing, W Ruijssenaars, D Aalsvoort (toim.) Learning potential assessment and cognitive training: Actual research perspectives in theory building and methodology. JAI Press/ Elsevier, New York.

Ungerleider LG, Mishkin M (1982) Two cortical visual systems. Teoksessa DJ Ingle, MA Goodale, RJW Mansfield (toim.) Analysis of visual behavior. MIT Press, Cambridge, MA.

Uttal DH, Meadow NG, Tipton, E, Hand LL, Alden AR, Warren C (2012) The malleability of spatial skills: A meta-analysis of training studies. Psychological Bulletin 2, 352-402.

Van Der Heyden AM, Witt JC, Gilbertson D (2007) A multi-year evaluation of the effects of a Response to Intervention (RTI) model on identification of children for special education. Journal of School Psychology 2, 225-256.

Vanni S (2006) Näköjärjestelmä ja visuaalinen havaintomaailma. Teoksessa H Hämäläinen, M Laine, 0 Aaltonen, A Revonsuo (toim.) Mieli ja aivot. Kognitiivisen neurotieteen oppikirja. Kognitiivisen neurotieteen tutkimuskeskus, Turun yliopisto. von Wendt L (2003) Lasten neurologinen kuntoutus. Teoksessa T Kallanranta, P Rissanen (toim.) Kuntoutus. Duodecim, Jyväskylä.

Vygotsky LS (1978) Interaction between Learning and Development. Teoksessa LS Vygotsky, M Cole (toim.) Mind in society. Harvard University Press, Cambridge, MA.

Willcutt EG, Doyle AE, Nigg JT, Faraone SV, Pennington BF (2005) Validity of the executive function theory of attention-deficit/hyperactivity disorder: A meta-analytic review. Biological Psychiatry 57, 1336-1346. 